\title{
Lovastatin inhibits the production of gibberellins but not sterol or carotenoid biosynthesis in Gibberella fujikuroi
}

\author{
Walter Giordano, ${ }^{1}$ Javier Avalos, ${ }^{2}$ Rafael Fernández-Martín, ${ }^{2}$ \\ Enrique Cerdá-Olmedo ${ }^{2}$ and Carlos E. Domenech ${ }^{1}$
}

Author for correspondence: Carlos E. Domenech. Tel: +54 58 676114. Fax: +54 58676232. e-mail:cdomenech@exa.unrc.edu.ar

\footnotetext{
1 Departamento de Biología Molecular, Universidad Nacional de Río Cuarto, 5800 Río Cuarto, Córdoba, Argentina

2 Departamento de Genética, Universidad de Sevilla, Sevilla, Spain
}

Sterols, carotenoids and gibberellins are synthesized after the reduction of 3 hydroxy-3-methylglutaryl coenzyme A (HMG-CoA) to mevalonate in different subcellular compartments of the fungus Gibberella fujikuroi. Lovastatin inhibits growth in many organisms, presumably because of the inhibition of the synthesis of essential terpenoids. However, in G. fujikuroi growth of the mycelia and sterol and carotenoid content were not affected by the presence of lovastatin. Nevertheless, lovastatin did inhibit the accumulation of gibberellins in the culture medium; this inhibition, however, was counteracted by the addition of mevalonate to the medium. The conversion of HMG-CoA to mevalonate in cell-free extracts was inhibited by $10 \mathrm{nM}$ lovastatin. Since $G$. fujikuroi apparently possesses a single gene for HMG-CoA reductase, as shown by Southern hybridization and PCR amplification, it was concluded that the biosynthesis of sterols, carotenoids and gibberellins shares a single HMG-CoA reductase, but the respective subcellular compartments are differentially accessible to lovastatin.

Keywords: lovastatin, terpenoids, gibberellins, HMG-CoA reductase, Gibberella fujikuroi

\section{INTRODUCTION}

Terpenoids are a large, varied and widespread group of natural compounds. The terpenoids synthesized by the fungus Gibberella fujikuroi include carotenoids, responsible for the orange pigmentation of the mycelium, and gibberellins, which act as hormones in plants (Rademacher, 1997). Important physiological functions are carried out in cells by sterols, dolichols, ubiquinone, and farnesyl and geranylgeraniol groups added to many proteins (Chappell, 1995a, b).

All natural terpenoids are derived from geranyl diphosphate (Mende et al., 1997). The sterols, gibberellins and carotenoids of $G$. fujikuroi are synthesized through a pathway that includes 3-hydroxy3-methylglutaryl coenzyme A (HMG-CoA) and Dmevalonate (Coolbaugh, 1983; Domenech et al., 1996). These intermediaries are not used in an alternative pathway as found in other organisms, which starts with

Abbreviation: HMG-CoA, 3-hydroxy-3-methylglutaryl coenzyme A. glyceraldehyde 3-phosphate and pyruvate (Rohmer et al., 1993).

Labelling experiments led to the conclusion that the pathways for different terpenoids, including their common sections, must occur in different cellular compartments. This is the case for carotene and sterol biosyntheses in Phycomyces blakesleeanus (Bejarano \& Cerdá-Olmedo, 1992), and carotenoid, sterol and gibberellin biosyntheses in G. fujikuroi (Domenech et al., 1996). Terpenoid biosynthesis in different compartments was also shown in animals (Biardi \& Krisans, 1996) and, as metabolic channels, in plants (Chappell, 1995b).

HMG-CoA reductase (EC 1.1.1.34) catalyses the conversion of HMG-CoA to mevalonate. Genes for this enzyme have been isolated from several organisms. All of them contain a highly conserved, hydrophilic catalytic domain and a variable number of less conserved transmembrane domains (Hampton et al., 1996). Whereas in animals there appears to be only one gene for HMG-CoA reductase, two or more genes have been found in Saccharomyces cerevisiae and in different plants (Basson et al., 1988; Chappell, 1995a). A gene 
from G. fujikuroi can be readily isolated using degenerate oligonucleotides with sequences that are highly conserved in all homologous genes (Corrochano \& Avalos, 1992; Woitek et al., 1997).

A powerful inhibitor of this enzyme is a compound now most frequently called lovastatin, previously known as monacolin $\mathrm{K}$ when isolated from Monascus ruber and mevinolin when isolated from Aspergillus terreus (Endo \& Hasumi, 1997). Lovastatin inhibits growth in many organisms, often at very low concentrations, presumably because of the inhibition of the synthesis of essential terpenoids (Florin-Christensen et al., 1990; Lam \& Doolittle, 1992; Haag et al., 1994; Morehead et al., 1995).

In this paper we show that while lovastatin did not significantly affect the growth and production of sterols and carotenoids in G. fujikuroi, it did inhibit its gibberellin production. Our results support the existence of independent compartments for the biosynthesis of various terpenoids in this fungus.

\section{METHODS}

Strains and culture conditions. This work was carried out utilizing the standard wild-type strain IMI 58289 of $G$. fujikuroi and its mutant strain SG22. Since the wild-type strain produces very few carotenoids, we utilized strain SG22. This strain is particularly suitable for the detection of effects on carotenoid biosynthesis since it accumulates mostly neurosporaxanthin at a constant high rate over a period of many days (Avalos \& Cerdá-Olmedo, 1987). Both strains were grown from spores in $125 \mathrm{ml}$ Erlenmeyer flasks containing $25 \mathrm{ml}$ low-nitrogen minimal liquid medium, and incubated at $30{ }^{\circ} \mathrm{C}$ in an orbital shaker (about 150 r.p.m.). The minimal medium (Geissman et al., 1966) contained $80 \mathrm{~g} \mathrm{D-glucose} \mathrm{l}^{-1}$ as carbon source and $0.48 \mathrm{~g} \mathrm{NH}_{4} \mathrm{NO}_{3} \mathrm{l}^{-1}$ as the nitrogen source. Each flask was inoculated with approximately $10^{6}$ spores collected from a culture grown in a Petri dish with sporulation agar (Avalos et al., 1985). After growth, mycelium was collected by filtration, washed with water, and lyophilized, or dried for $3 \mathrm{~h}$ at $105^{\circ} \mathrm{C}$, before determination of dry weights. Under our experimental conditions, gibberellin biosynthesis started after $3 \mathrm{~d}$ vegetative growth, following the exhaustion of the nitrogen source (Candau et al., 1992).

Biochemical analyses. Carotenoids were extracted with acetone and the dried extracts were redissolved in n-hexane for spectrophotometry. The total amounts of coloured carotenoids (Fernández-Martín et al., 1995) or ergosterol (Domenech et al., 1996) were estimated from absorbance determinations. The total gibberellin concentrations in culture media were estimated fluorometrically (Candau et al., 1991) after removal of mycelium by filtration.

To assay HMG-CoA reductase, washed mycelium was frozen in liquid nitrogen, ground in a mortar, and extracted by suspension in HEPES/sucrose/ $\mathrm{NaCl} / \mathrm{EDTA} / \mathrm{EGTA}$ buffer, $\mathrm{pH} 7 \cdot 4$, plus protease inhibitors as described by Peña-Díaz et al. (1997). The lysate was then cleared by centrifugation at $1000 \mathrm{~g}$ for $2 \mathrm{~min}$. HMG-CoA reductase was assayed by utilizing $25-50 \mu \mathrm{g}$ protein from the supernatant and DL-3hydroxy-3-methyl-[3- ${ }^{14}$ C]glutaryl-CoA (Amersham International) as substrate as described by Shapiro et al. (1974) with the modification of Peña-Díaz et al. (1997). Each sample contained $0.4 \mathrm{mM}$ of the radioactive substrate (specific radioactivity: 2550 d.p.m. nmol ${ }^{-1}$ ), 25 mM EDTA, 1.6 mM DTT, $30 \mathrm{mM}$ glucose 6-phosphate, $3 \mathrm{mM}$ NADP, 50 milliunits glucose-6-phosphate dehydrogenase in a final volume of $75 \mu \mathrm{l}$. Under the assay conditions described the determinations were linear up to at least $30 \mathrm{~min}$ incubation. To study the effect of lovastatin in vitro, it was added, as the sodium salt, to cell-free extracts at concentrations indicated in the text or figures. The activity of HMG-CoA reductase was expressed as pmol HMGCoA converted to mevalonate $\min ^{-1}(\mathrm{mg} \text { protein })^{-1}$. Protein was determined as described by Bradford (1976), using BSA as standard. The analytical results are the mean and its standard error from three independent experiments.

Genomic DNA isolation. Genomic DNA was isolated following a modification of the method described by Sherman et al. (1986). Mycelium was obtained by filtration of a culture of $10^{6}$ spores incubated for $2 \mathrm{~d}$ at $30^{\circ} \mathrm{C}$ in an orbital shaker in $200 \mathrm{ml}$ minimal medium (Avalos et al., 1985) supplemented with $1 \mathrm{~g}$ yeast extract $\mathrm{l}^{-1}$. The mycelial pad was washed with water, dried with filter paper, covered with liquid nitrogen in a precooled mortar and quickly ground to a fine powder. The latter was mixed immediately with $7.5 \mathrm{ml}$ Tris/EDTA $(50 \mathrm{mM}$ Tris, $20 \mathrm{mM}$ EDTA, pH 7.5) and $0.5 \mathrm{ml} \mathrm{SDS}\left(100 \mathrm{~g} \mathrm{l}^{-1}\right)$ and heated at $65^{\circ} \mathrm{C}$ for $30 \mathrm{~min}$. It was then mixed with $2 \cdot 3 \mathrm{ml} 5 \mathrm{M}$ potassium acetate, maintained at $4{ }^{\circ} \mathrm{C}$ for $30-60 \mathrm{~min}$, and centrifuged at $9000 \mathrm{~g}$ for $10 \mathrm{~min}$. The supernatant was filtered through a gauze, mixed with 2 vols ethanol, and incubated overnight at $4{ }^{\circ} \mathrm{C}$ before centrifugation at $9000 \mathrm{~g}$ for $10 \mathrm{~min}$. The pellet was washed twice with ethanol $\left(700 \mathrm{ml} \mathrm{l}^{-1}\right)$, suspended in $3 \mathrm{ml}$ Tris/EDTA, and treated with $15 \mu \mathrm{l}$ bovine pancreas ribonuclease A $\left(10 \mathrm{~g} \mathrm{l}^{-1}\right)$ for $30 \mathrm{~min}$ at $37^{\circ} \mathrm{C}$. The sample was mixed with $2 \mathrm{ml}$ phenol/chloroform/isoamyl alcohol $(25: 24: 1$, by vol.) to stop digestion and centrifuged at $3500 \mathrm{~g}$ for $5 \mathrm{~min}$. The water fraction was washed twice with chloroform/isoamyl alcohol $(15: 1, \mathrm{v} / \mathrm{v})$, transferred to a new clean tube, mixed with 1 vol. 2-propanol, and centrifuged at $1000 \mathrm{~g}$ for $5 \mathrm{~min}$. The precipitate was washed twice with ethanol $\left(700 \mathrm{ml} \mathrm{l}^{-1}\right)$, dried and resuspended in $0.5 \mathrm{ml}$ Tris/ EDTA solution.

Southern hybridization and PCR replication. Genomic DNA (approx. $5 \mu \mathrm{g}$ ) was digested overnight with the indicated restriction enzymes. It was then separated by electrophoresis in an agarose gel $(1 \%)$, and transferred to a nylon membrane (Hybond; Amersham). Hybridization was carried out with a $318 \mathrm{bp}$ fragment of the G. fujikuroi gene for HMG-CoA reductase, obtained by in vitro PCR replication of genomic DNA using the primers described by Corrochano \& Avalos (1992), labelled with digoxigenin-11-dUTP. Detection was carried out with a chemiluminescent substrate (CSPD) following the manufacturer's recommendations (Boehringer Mannheim). Hybridization and washing were carried out at $65^{\circ} \mathrm{C}$. For other DNA manipulations and technical details see Sambrook et al. (1989).

\section{RESULTS}

\section{Effects of lovastatin and mevalonate}

The wild-type and the SG22 mutant of G. fujikuroi resisted high concentrations of lovastatin in the culture medium. Growth was not inhibited in the presence of up to $5 \mu \mathrm{M}$ lovastatin. Table 1 shows that lovastatin did not affect the production of essential terpenoids such as sterols, and dispensable ones such as carotenoids. In contrast, lovastatin inhibited the accumulation of 
Table 1. Effects of lovastatin on growth and terpenoid production

Mycelial dry weight $\left(\mathrm{g} \mathrm{l}^{-1}\right)$, sterols, carotenoids and gibberellins [mg $\left(\mathrm{g} \mathrm{dry} \mathrm{wt}^{-1}\right.$ ] after $7 \mathrm{~d}$ growth in the absence or in the presence of $5 \mu \mathrm{M}$ lovastatin in the culture medium.

\begin{tabular}{|c|c|c|c|c|}
\hline & \multicolumn{2}{|c|}{ - Lovastatin } & \multicolumn{2}{|c|}{+ Lovastatin } \\
\hline & Wild-type & SG22 & Wild-type & SG22 \\
\hline Dry weight & $6 \cdot 8 \pm 0 \cdot 7$ & $6 \cdot 3 \pm 0 \cdot 2$ & $6 \cdot 6 \pm 0 \cdot 4$ & $6 \cdot 0 \pm 0 \cdot 4$ \\
\hline Sterols & $5 \cdot 3 \pm 0 \cdot 8$ & $5 \cdot 6 \pm 0 \cdot 9$ & $5 \cdot 6 \pm 0 \cdot 4$ & $5 \cdot 4 \pm 0 \cdot 5$ \\
\hline Carotenoids & $<0.02$ & $1 \cdot 7 \pm 0 \cdot 2$ & $<0.02$ & $1 \cdot 5 \pm 0 \cdot 1$ \\
\hline Gibberellins & $5 \cdot 3 \pm 0 \cdot 5$ & $2 \cdot 5 \pm 0 \cdot 5$ & $2 \cdot 7 \pm 0 \cdot 2$ & $1 \cdot 3 \pm 0 \cdot 1$ \\
\hline
\end{tabular}
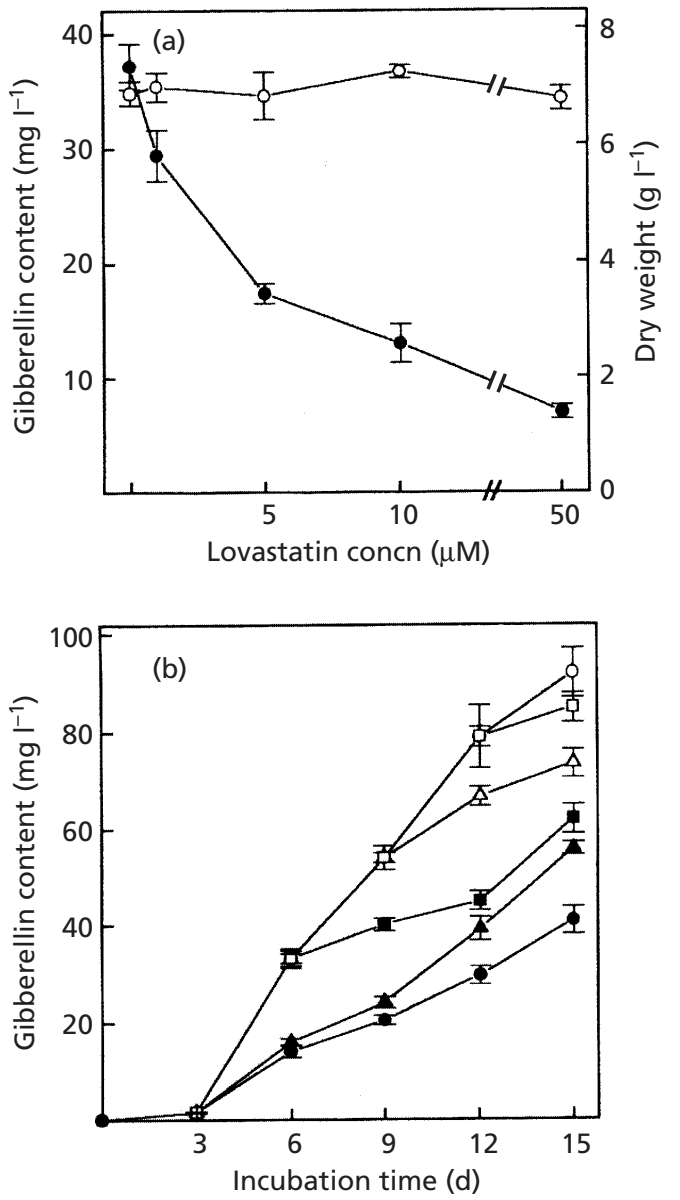

Fig. 1. Inhibition of gibberellin biosynthesis by lovastatin. (a) Gibberellin content $(\bullet)$ and mycelial dry weight $(O)$ in the culture media of G. fujikuroi wild-type IMI 58289 incubated for $7 \mathrm{~d}$ in the presence of different concentrations of lovastatin. (b) Gibberellin content in the culture media of strain IMI 58289. Lovastatin (final concentration $5 \mu \mathrm{M}$ ) was added initially (๑), or to cultures aged $3 \mathrm{~d}(\boldsymbol{\Delta}), 6 \mathrm{~d}(\boldsymbol{\square}), 9 \mathrm{~d}(\triangle)$ and $12 \mathrm{~d}(\square)$. $O$, No addition of lovastatin.

gibberellins in the culture medium. The inhibition was dose-dependent (Fig. 1a) and occurred whether the inhibitor was initially present in the medium or was
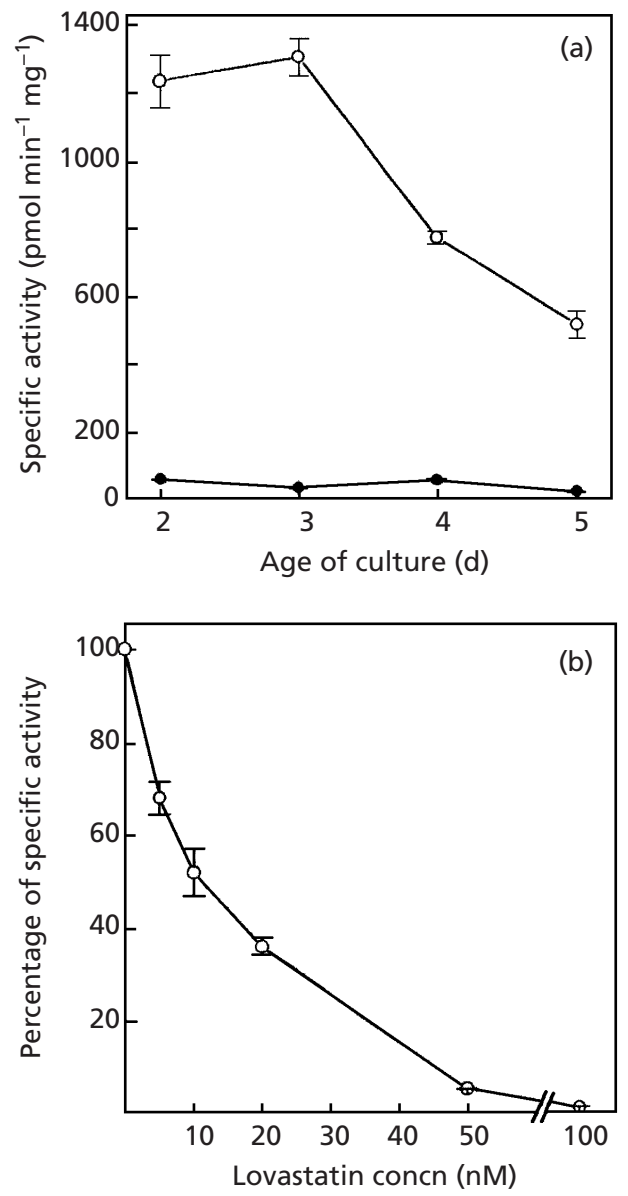

Fig. 2. In vitro effect of lovastatin on HMG-CoA reductase activity measured in cell-free extracts of mycelia from cultures of strain SG22. (a) Enzyme activity in the presence (0) or absence (O) of $100 \mathrm{nM}$ lovastatin. (b) Effect of different concentrations of lovastatin on HMG-CoA reductase activity from mycelia grown for $3 \mathrm{~d}$.

added to cultures already engaged in gibberellin production (Fig. 1b). The inhibition by lovastatin was counteracted by the addition of mevalonate. The gibberellin content of 10-d-old cultures initially supplemented with $5 \mu \mathrm{M}$ lovastatin was $24 \pm 1.5 \mathrm{mg} \mathrm{l}^{-1}$, but reached $64 \pm 6 \cdot 1$ if supplemented with $10 \mathrm{mM}$ DL- 
(a)

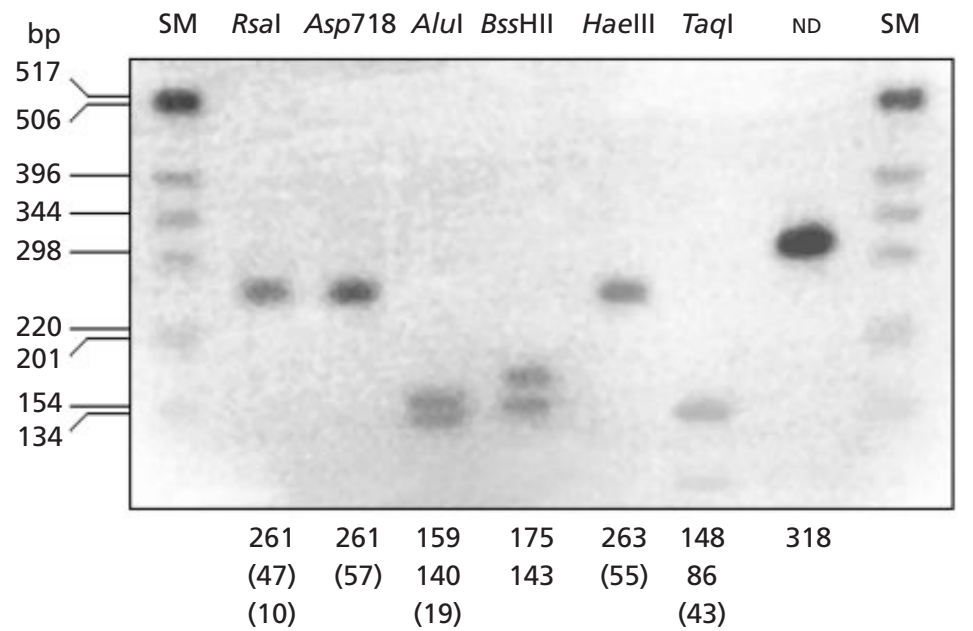

(41)

(b)

$$
\begin{array}{cr}
\text { TaqI HaeIII } \\
\text { AGT CGA }
\end{array}
$$

G. fujikuroi A. glauca

B. trispora C. utilis

D. discoideum

M. mucedo 1

M. mucedo 2

P. parasitica I

$P$. parasitica 2

P. blakesleeanus

S. manthoticola

S. cerevisiae 1

S. cerevisiae 2

S. pombe

U. maydis

PMATTEG VILVASAS RGGCKA INS GGGA ITVL TAID GMT

PMATTEGCLLASAAAGCKA I DAGGGAWT $\vee \vee T A D G M T$

PMATTEGCLLASTA RGCKA INAGGGANTII V VADGMT

PMATTEGCL VAS AM RGCKA IN L G GGVTTVL TKD GMT

PMATTEGCL VASTHRGAKA I TKSTGG AKT VL LQSGMT

PMATTEGCLLASTARGCKA IN]AGGGATTI V I ADGMT

PMATTEGCLIAS AA RGCKA I NMGGGATT I I TAD GMT

PMATTEGCL VAS AARGCKA INAGGGATTI $V$ I ADGMT

PMATTEGCLIASAARGCKA I NAGSGATTII TAD GMT

PMATTEGCL VAS TA RGCKA INAGGGASTI V I AD GMT

PMATTEGVL VAS TS RGCKA INAGGGAVTVL TAD GMT

PMATTEGCL VAS AMRGCKA INAGGGATTVL TKD GMT

PMATTEGCL VAS AM RGCKA INAGGGATTVL TKDGMT

PMATTEGAL VASTMRGCKA INAGGGAVTVL TRDQMS

PMATTEGTL VAS TS BGCKALNAGGGVTVLTQDAMT

$$
\text { Taq } \mathrm{I} B s \mathrm{HI} \quad A l u \mathrm{I} \quad A l u \mathrm{I}
$$

TTC GAG GAGCGCGCT A CTC GAA GCT

G. fuickuroi RGPICVAAFE TL E RAAG - A ATKLTWLDS EATGQDMMK KAFNS

A. glauca

B. trispora C. utilis

D. discoideum

M. mucedo 1

M. mucedo 2

P. parasitica 1

P. parasitica 2

P. blakesleeanus

S. manihoticola

S. cerevisiae 1

S. cerevisiae 2

S. pombe

U. maydis

RGPIVEFPT VL RAA - ECKRWIEO- EGNTILTDAFN

RGPC VE FPT I T RAA - D C K RW I EQ- EGEAI VT EAFNS

RGPC VK FPS L K RAG - QC KLWLDSD EGQEEMK KAFNS

RAP VCRLPS S I RAG - E L KQWI ENQEN FYQVAS AFN S

$R G P C D E E P N \mid T R A A$ - D C KRW I EQ - EGEA I VT GAFN S

RGPCVE FPS I VGAA - AC KRF I ED - EGLEI I TNAFNS

RGPC VE FPN I L RAA - DC K R/W] EQ - EGEKVVT EAFN S

RGPCVEFPS I VGAA - ACKRFIEE - EGAAI I TDAFNS

RGPCVEFPTIL RAA - ACKLWIEN - EGNDI VTNAFNS

RGPCVG FETL A RAAAA A KL WLLSEEGQK VMKDAFN S

RGP VVR F PT L K RSG - AC K I WLDSEEGQNA I K KAFNS

RGPVVRFPTL I RSG - ACK I WLDSEEGQNS I K KAFNS

RGPC VA FPD LTRAG - RAKIIWLDS PEGQEVMKKAFNS

RGPALE FPS $V \vee Q A A-K A K$ RW I DSQEGAQT I K AAFDS

$$
\begin{gathered}
\text { Asp718/RsaI RsaI TaqI } \\
\text { GGT ACC CTG TAC ATT CGA }
\end{gathered}
$$

G. fuitikuroi

A. glauca

B. trispora C. utilis

D. discoideum

M. nucedo 1

M. mucedo 2

P. parasitica 1

P. parasitica 2

P. blakesleeanus

S. manihoticola

S. cerevisiae 1

S. cerevisiae 2

S. pombe

U. maydis
TS RFA RLLS MKTATAGTN $L$ Y RFKTTTGDAMGMNM TS RFA RL RKLKVALAGKLVF। RFSTTTGDAMGMNM TS RFA RVRKL KVALAGRL VY RFST TTGDAMGMNM TS RFA RLQHL QTALAGDLLF I RFRT VTGDAMGMNM TS RFA RLKS I KVVTAGRL VYLRFISSTGDAMGMNM TS RFA RVRKL KVALAG RL VY I RFSTTTGDAMGMNM TS RFA RLRKMK VAMAGKL VF I RFST TTGDAMGMNM TS RFA RVRKMKVALAGCLMY I RFST TTGDAMGMNM TS RFA RL RKL KVAL AGRL VF I RFST TTGDAMGMNM TS RFA RL RKL K I ALAGKL VF I RFST TTGDAMGMNM TS RFA RLQQL KTSLAGTYVY I RFKTTTGEAMGMNM TS RFA RLQH IQTCLAGDLLFMRFRT TTGDAMGMNM TS RFA RLQH I QTCL A GD L LFMRFRT TTG D A MGMNM TS RFA RLQH I KTALAGTRLF I RFCTS TGDAMGMNM TS RFA RLS SL RC VL AGRTL Y VRFATSTGDAMGMNM
Fig. 3. (a) Electrophoretic separation of a PCR amplicon product from strain IMI 58289 with oligonucleotide primers for two conserved sequences from the HMG-CoA reductase genes of various organisms. The DNA product was digested with the restriction enzymes indicated in the corresponding lanes. Expected fragment sizes are shown below each lane; fragments can be seen up to $86 \mathrm{bp}$. ND, Non digested; SM, size markers. (b) Comparison of the amino acid sequences encoded by the PCR product of the G. fujikuroi HMG-CoA reductase gene (Corrochano \& Avalos, 1992) and the homologous DNA sequences from the fungal HMG-CoA reductase genes available in protein databases. Boxes indicate residues present in the same position of at least $75 \%$ of the protein sequences. Correspondence between targets for restriction enzymes and amino acid codons is indicated on the G. fujikuroi protein sequence. Species are Absidia glauca, Blakeslea trispora, Candida utilis, Dictyostelium discoideum, Mucor mucedo, Parasitella parasitica, Phycomyces blakesleeanus, Sphaceloma manihoticola, Saccharomyces cerevisiae, Schizosaccharomyces pombe and Ustilago maydis. 


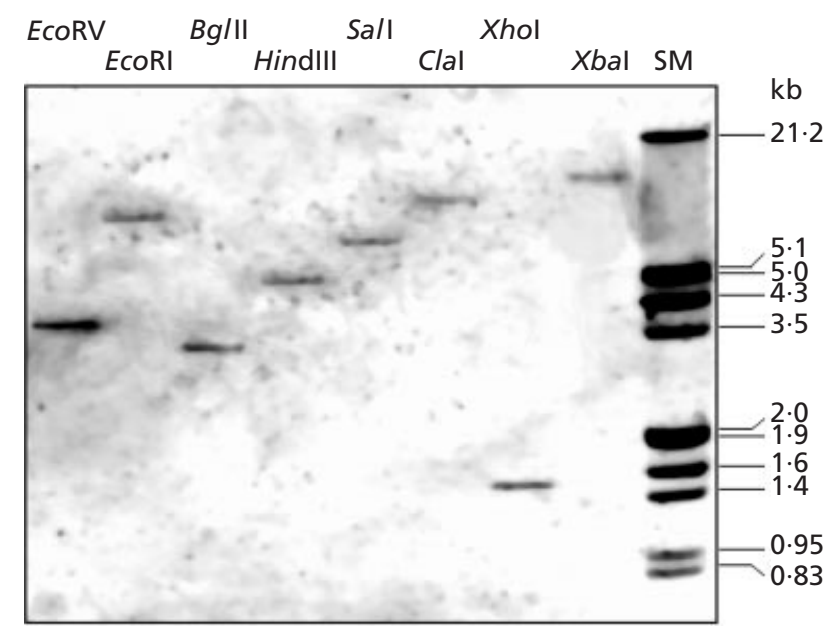

Fig. 4. Hybridization of a fragment of the G. fujikuroi HMGCoA reductase gene with genomic DNA of strain IMI 58289 digested with restriction enzymes indicated in the corresponding lanes. SM, Size markers.

mevalonate at the age of $3 \mathrm{~d}$. Control cultures without lovastatin or mevalonate contained $68 \pm 4.5 \mathrm{mg} \mathrm{l}^{-1}$.

\section{Reduction of HMG-CoA by cell-free extracts}

Radioactively labelled HMG-CoA was converted to mevalonate by cell-free extracts of G. fujikuroi. The highest activity was found in young cultures, 2 or $3 \mathrm{~d}$ old (Fig. 2a), and declined with the cessation of balanced growth, the exhaustion of the nitrogen source, and the onset of gibberellin production (Candau et al., 1992). The activity was very sensitive to lovastatin : addition of $10 \mathrm{nM}$ lovastatin to the extracts lowered their activity to about one-half of the original activity, and addition of $100 \mathrm{nM}$ rendered it practically undetectable (Fig. 2b). Treatments either by sonication or with $0 \cdot 05-1 \%$ Triton X-100 of the cell-free extracts did not produce changes in the enzyme activity.

\section{PCR and Southern blot analysis}

The DNA molecule obtained by PCR with the two oligonucleotide mixtures treated with different restriction enzymes (Fig. 3a) was coincident with that expected from the sequence of the gene already known (Fig. 3b). The same fragment (Fig. 3b) used as a probe to detect the DNA fragments separated by gel electrophoresis after complete digestion of the genome of this fungus with eight different restriction enzymes led to the detection of a single DNA band in each case (Fig. 4). Repetition at lower annealing and washing temperatures did not reveal additional specific bands.

\section{DISCUSSION}

G. fujikuroi grows and produces carotenoids in the presence of high concentrations of lovastatin in the culture medium. This is not the case for other organisms; thus, P. blakesleeanus does not grow in the presence of $1 \mu \mathrm{M}$ lovastatin (Bejarano \& Cerdá-Olmedo, 1992). The inhibition of gibberellin biosynthesis in $G$. fujikuroi (Shiao, 1983; Lewer \& McMillan, 1983) is a surprising observation in view of the lack of inhibition of the synthesis of all essential terpenoids and of carotenoids. Since sterols, carotenoids and gibberellins are synthesized in different subcellular compartments (Domenech et al., 1996), the inhibition of gibberellin biosynthesis by lovastatin and the lack of effect on growth and pigmentation would be explained if the respective subcellular compartments are not equally accessible to lovastatin. In support of this point is the fact that the HMG-CoA reductase is very sensitive to lovastatin in vitro, but differentially sensitive to lovastatin in vivo. Therefore, the above results may be explained by postulating the physical separation of the terpenoid pathways.

The second point supporting the idea that the enzyme is not freely accessed by its inhibitor are the results obtained by Southern hybridization and PCR amplification. The results of both types of experiments led to conclusions very similar to those reported by Woitek et al. (1997) for different strains of G. fujikuroi. HMGCoA reductase appears to be the product of a single gene. The restriction pattern of the PCR product is especially informative: our mixture of primer oligonucleotides should have allowed detection of all known genes for HMG-CoA reductases (Corrochano \& Avalos, 1992), but amplification resulted in only one DNA sequence that appears to be unique. Although a single hybridizing band in a genomic Southern blot may constitute proof that a gene is present in one copy per haploid genome, our results do not rule out the fact that a tandemly repeated gene array would give the same pattern of hybridization.

An independent explanation would be that lovastatin inhibits not only HMG-CoA reductase, but also a step specific for gibberellin biosynthesis. This would require different compartmentation, with only the latter step accessible to lovastatin in vivo. The normal gibberellin biosynthesis in the presence of lovastatin and mevalonate suggests that gibberellins are produced freely from mevalonate in the presence of lovastatin. Mevalonate should have a regulatory effect of its own that leads to a total blockage of gibberellin production when present initially in the culture media (Domenech et al., 1996); for this reason mevalonate was added to 3-d-old cultures.

Alternatively, G. fujikuroi could possess two HMGCoA reductases. The essential terpenoids and the carotenoids would be made by an enzyme belonging to a wholly new sequence class, resistant to lovastatin, and undetectable in the in vitro assay. This hypothesis, however, lacks experimental support and is contrary to observations of enzymes from numerous organisms.

\section{ACKNOWLEDGEMENTS}

This work was supported by grants from the Consejo Nacional de Investigaciones Científicas y Técnicas 
(CONICET), Consejo de Investigaciones Científicas y Tecnológicas de la Provincia de Córdoba (CONICOR), the Spanish Government (DGES PB96-1336, Programa de Colaboración con Iberoamérica), Junta de Andalucía (Group CVI0119) and the European Union (FAIR CT96-1633). C.E.D. is a Career Member of the CONICET and W. G. has a fellowship from the CONICET of the República Argentina. We thank Drs D. Gonzalez-Pacanowska and A. Montalvetti for useful help in the assay of HMG-CoA reductase activity.

\section{REFERENCES}

Avalos, J. \& Cerdá-Olmedo, E. (1987). Carotenoid mutants of Gibberella fujikuroi. Curr Genet 11, 505-511.

Avalos, J., Casadesús, J. \& Cerdá-Olmedo, E. (1985). Gibberella fujikuroi mutants obtained with UV radiation and N-methyl- $N^{\prime}$ nitro-N-nitrosoguanidine. Appl Environ Microbiol 49, 187-191.

Basson, M. E., Thorsness, M., Finer-Moore, J., Stroud, R. M. \& Rine, J. (1988). Structural and functional conservation between yeast and human 3-hydroxy-3-methylglutaryl coenzyme A reductases, the rate limiting enzyme of sterol biosynthesis. Mol Cell Biol 8, 3797-3808.

Bejarano, E. R. \& Cerdá-Olmedo, E. (1992). Independence of the carotene and sterol pathways of Phycomyces. FEBS Lett 306, 209-212.

Biardi, L. \& Krisans, S. K. (1996). Compartmentalization of cholesterol biosynthesis. Conversion of mevalonate to farnesyl diphosphate occurs in the peroxisomes. J Biol Chem 271, 1784-1788.

Bradford, M. M. (1976). A rapid and sensitive method for the quantitation of microgram quantities of protein utilizing the principle of protein-dye binding. Anal Biochem 72, 248-254.

Candau, R., Avalos, J. \& Cerdá-Olmedo, E. (1991). Gibberellins and carotenoids in the wild type and mutants of Gibberella fuikuroi. Appl Environ Microbiol 57, 3378-3382.

Candau, R., Avalos, J. \& Cerdá-Olmedo, E. (1992). Regulation of gibberellin biosynthesis in Gibberella fujikuroi. Plant Physiol 100, 1184-1188.

Chappell, J. (1995a). The biochemistry and molecular biology of isoprenoid metabolism. Plant Physiol 107, 1-6.

Chappell, J. (1995b). Biochemistry and molecular biology of the isoprenoid biosynthetic pathway in plants. Annu Rev Plant Physiol Mol Biol 46, 521-547.

Coolbaugh, R. C. (1983). Early stages of gibberellin biosynthesis. In The Biochemistry and Physiology of Gibberellins, pp. 53-98. Edited by A. Crozier. New York: Praeger.

Corrochano, L. M. \& Avalos, J. (1992). Cloning a segment of the gene encoding 3-hydroxy-3-methylglutaryl Coenzyme A reductase in Phycomyces blakesleeanus and Gibberella fujikuroi by the polymerase chain reaction. Exp Mycol 16, 167-171.

Domenech, C. E., Giordano, W., Avalos, J. \& Cerdá-Olmedo, E. (1996). Separate compartments for the production of sterols, carotenoids, and gibberellins in Gibberella fujikuroi. Eur J Biochem 239, 720-725.

Endo, A. \& Hasumi, K. (1997). Mevinic acids. In Fungal Biotechnology, pp. 162-172. Edited by T. Anke. Weinheim: Chapman \& Hall.

Fernández-Martín, R., Reyes, F., Domenech, C. E., Cabrera, E., Bramley, P. M., Barrero, A. F., Avalos, J. \& Cerdá-Olmedo, E.
(1995). Gibberellin biosynthesis in gib mutants of Gibberella fujikuroi. J Biol Chem 270, 14970-14974.

Florin-Christensen, M., Florin-Christensen, J., Garin, C., Isola, E., Brenner, R. R. \& Rasmussen, L. (1990). Inhibition of Trypanosoma cruzi growth and sterol biosynthesis by lovastatin. Biochem Biophys Res Commun 166, 1441-1445.

Geissman, T. A., Verbiscar, A. J., Phinney, B. O. \& Cragg, G. (1966). Studies on the biosynthesis of gibberellins from (-)kaurenoic acid in cultures of Gibberella fujikuroi. Phytochemistry 5, 933-947.

Haag, H., Grünberg, B., Weber, C., Vauti, F., Aepfelbacher, M. \& Siess, W. (1994). Lovastatin inhibits receptor-stimulated $\mathrm{Ca}\left(2^{+}\right)$influx in retinoic acid differentiated U937 and HL-60 cells. Cell Signal 6, 735-742.

Hampton, R., Dimster-Denk, D. \& Rine, J. (1996). The biology of HMG-CoA reductase: the pros of contra-regulation. Trends Biochem Sci 21, 140-145.

Lam, W. L. \& Doolittle, W. F. (1992). Mevinolin-resistant mutations identify a promoter and the gene for a eukaryote-like 3hydroxy-3-methylglutaryl-coenzyme A reductase in the archaebacterium Haloferax volcanii. J Biol Chem 267, 5829-5834.

Lewer, P. \& MacMillan, J. (1983). Effect of compactin on the incorporation of mevalonolactone into gibberellic acid by Gibberella fujikuroi. Phytochemistry 22, 602-603.

Mende, K., Homann, V. \& Tudzynski, B. (1997). The geranylgeranyl diphosphate synthase gene of Gibberella fujikuroi: isolation and expression. Mol Gen Genet 255, 96-105.

Morehead, T. A., Biermann, B. J., Crowell, D. N. \& Randall, S. K. (1995). Changes in protein isoprenylation during the growth of suspension-cultured tobacco cells. Plant Physiol 109, 277-284.

Peña-Díaz, J., Montalvetti, A., Camacho, A., Gallego, C., RuizPerez, L. M. \& Gonzalez-Pacanowska, D. (1997). A soluble 3hydroxy-3-methylglutaryl-CoA reductase in the protozoan Trypanosoma cruzi. Biochem J 324, 619-626.

Rademacher, W. (1997). Gibberellins. In Fungal Biotechnology, pp. 193-205. Edited by T. Anke. Weinheim: Chapman \& Hall.

Rohmer, M., Knani, M., Simonin, P., Sutter, B. \& Sahm, H. (1993). Isoprenoid biosynthesis in bacteria: a novel pathway for the early steps leading to isopentenyl diphosphate. Biochem J 295, 517-524.

Sambrook, J., Fritsch, E. F. \& Maniatis, T. (1989). Molecular Cloning: a Laboratory Manual, 2nd edn. Cold Spring Harbor, NY : Cold Spring Harbor Laboratory.

Shapiro, D. J., Nordstrom, J. L., Mitschelen, J. J., Rodwell, V. W. \& Schimke, R. T. (1974). Micro assay for 3-hydroxy-3methylglutaryl-CoA reductase in rat liver and in L-cell fibroblasts. Biochim Biophys Acta 370, 369-377.

Sherman, F., Fink, G. R. \& Hicks, J. B. (1986). Laboratory Course Manual for Methods in Yeast Genetics. Cold Spring Harbor, NY: Cold Spring Harbor Laboratory.

Shiao, M. S. (1983). Inhibition of gibberellin biosynthesis in Gibberella fujikuroi and germination of Oryza sativa by mevinolin. Bot Bull Acad Sin 24, 135-143.

Takahashi, N., Phinney, B. O. \& MacMillan, J. (1991). Gibberellins. New York: Springer.

Woitek, S., Unkles, S. E., Kinghorn, J. R. \& Tudzynski, B. (1997). 3Hydroxy-3-methylglutaryl-CoA reductase gene of Gibberella fujikuroi: isolation and characterization. Curr Genet 31, 38-47.

Received 3 December 1998; revised 24 June 1999; accepted 5 July 1999. 